\title{
Relationship between mental symptoms, dietary compliance and glucose levels of diabetic patients in isolation during COVID-19 Pandemic
}

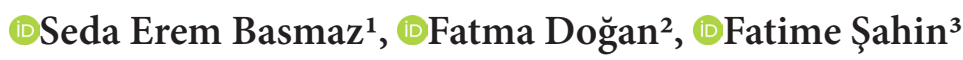 \\ ${ }^{1}$ Health Sciences University, Derince Training and Research Hospital,Department of Endocrinology and Metabolism Diseases, Kocaeli, Turkey \\ ${ }^{2}$ Tuzla State Hospital, Department of Psychiatry, İstanbul, Turkey \\ ${ }^{3}$ Karabük University, Karabük Training and Research Hospital, Karabük, Turkey
}

Cite this article as: Erem Basmaz S, Doğan F, Şahin F. Relationship between mental symptoms, dietary compliance and glucose levels of diabetic patients in isolation during COVID-19 Pandemic. J Health Sci Med 2022; 5(1): 189-194.

\begin{abstract}
Aim: Coronavirus disease 2019 (COVID-19, 2019-nCoV) which first appeared in Wuhan, China in December 2019 is a disease causing acute respiratory failure. Home isolation methods are used to control the disease all around the world and also in our country. In this study we planned to explain the relationship between some mental symptoms, diet compliance, frequency of blood glucose measurement and blood glucose levels in diabetic patients during home isolation.

Material and Method: In this study some questions about the frequency of blood glucose measurement, blood glucose levels, dietary compliance and mental states of the patients were asked on the phone and the patients were asked to give a score to the symptom severity. The notes were retrospectively screened.

Results: It is known that social isolation triggers the anxiety and depression. Anxiety and depression can increase the secretion of some hormones which leads high blood glucose levels (respectively $54.4 \%$ of those with $200-300 \mathrm{mg} / \mathrm{dl}, 91.7 \%$ of those with $>300 \mathrm{mg} / \mathrm{dl}$ don't follow their diets) in diabetic patients. These symptoms can reduce dietary compliance and frequency of the blood sugar measurement, therefore can make metabolic control of the diabetes difficult.

Conclusion: In this study, we found that blood glucose levels were very high and the frequency of blood glucose measurements were very low in the patients who had some mood changes and we saw that the patients did not follow on their diets. It is important to support patients mentally during this process. Training and following up should be used with some various methods.
\end{abstract}

Keywords: COVID 19, anxiety, home isolation, phone visits

\section{INTRODUCTION}

Coronavirus 2019 (COVID-19, 2019-nCoV) which first appeared in Wuhan, China in December 2019 is a disease causing acute respiratory failure (1). It has been defined as a serious health problem in the world. Diabetes and its comorbidities have high mortality risk (2). The severity of COVID-19 and its mortality course have been shown to be associated with cardiovascular diseases, diabetes, hypertension, chronic lung and kidney diseases, and cancers (3).

Elderly people and people with chronic disease such as diabetes and hypertension seem to be more vulnerable to coronavirus infection. It was reported that the overall proportion of diabetes in COVID-19 increased from $5.3 \%$ to $20 \%(4)$.
COVID-19 infection can rapidly proceed towards acute respiratory distress syndrome and septic shock, leading to multi-organ failure in diabetic patients. It is shown that diabetes is associated with the mortality increase (4).

As a general perception and epidemiological studies show that diabetes is thought to increase the mortality and morbidity during infectious diseases. It is not yet known if diabetes is a risk factor in the prognosis of COVID-19 infection. It is known that type 2 diabetes and obesity can cause chronic and low-level inflammation. Moreover viral infections can cause sharp fluctuations in glucose levels in diabetic patients (5). 
According to American Diabetes Federation, blood glucose monitoring is quite an important component for diabetes regulation (6). Glucose regulation in diabetic patients should be important during COVID-19 infection (4). Due to the increase in mortality and morbidity, especially in the elderly and people with chronic diseases, home quarantine has been applied to these people all over the world and in our country during COVID-19 infection.

During the pandemics social isolation and quarantine could trigger anxiety and depression. Similar situations have been observed in people who were kept away from the people they love, from their personal habits and lifestyles. This can cause disappointment, boredom and depression. Avoiding infectious diseases can increase anxiety. This anxiety situation may increase even more with improper social avoidance guidelines, less reliable media sources (7).

In 2003 severe acute respiratory syndrome (SARS) was accepted as an epidemic and it affected 8000 people in 30 countries. During this period several mental symptoms appeared in SARS patients. These mental symptoms are generally anxiety and depression. Between 2005 and 2006 in Hong Kong $47.8 \%$ of the 1394 patients with SARS were diagnosed with posttraumatic stress disorder and this situation continued for about 30 months in $25.6 \%$ of these patients (8).

A few studies have been conducted searching mental health situation of those surviving after natural disasters and infectious diseases. However, no study has been conducted to explain the relationship between the risk of infection and mental health in isolated individuals.

It is found out that $80 \%$ of the population were afraid of MERS infection during the MERS epidemic. Those who were isolated for more than two weeks after contacting people with MERS infection showed serious anxiety symptoms and fear. Mortality rate of MERS is well known and it is approximately around $20 \%$. Patients who were diagnosed with the disease and kept in isolation for more than 2 weeks developed fear. But the effects of the two-week isolation on mental health are not known (8).

During the infection, stress and anxiety can increase the secretion of some hormones (cortisol, catecholamine etc.) of which would increase the blood glucose levels and its complications in diabetic patients (4).

In this study we planned to explain the relationship between some mental symptoms, dietary compliance, frequency of blood glucose measurement, and blood glucose levels in diabetic patients during home isolation.

\section{MATERIAL AND METHOD}

This study was performed with the approval of the ethics committee of Medical University of Vienna in accordance with the principles of the Helsinki Declaration of 1964 and its further amendments. The study was carried out with the permission of Karabük University Ethics Committee (Date 18.06.2020, Decision No 2020/279).

Phone visits were made to patients regularly in our diabetic outpatient clinic. During the COVID-19 pandemic, we increased phone interviews with diabetic patients (n: 298) who had to stay at home. We asked the patients some questions about their ages, type of their diabetes, age of diabetes, usage of insulin, if they used insulin we asked the frequency of injections in a day, how many times they would measure their blood glucose, how their measurement levels (average of the last 3 measurements) and dietary compliance were. We also asked if they had any mental symptoms such as depression, anxiety, tension or excitement and wanted them to give a score (from 0 to 6). We chose our questions from the Turkish Version of the Brief Psychiatric Rating Scale. The reason why we reduced the number of questions was not to extend the call time on the phone. According to the scaling 0 is determined as none, 1-2 as mild, 3-4 as medium, 5-6 as severe. According to the scores given by the patients, those who selected mild and medium were given simple behavioral advice. Those who selected severe were suggested to take psychiatric control besides behavioral advice. If the patient's glucose levels were high and if they didn't follow their diets properly, they were advised to follow their diet and to come for a check-up especially. In this study the notes taken during the phone interviews were retrospectively screened.

\section{Statistical Analysis}

The information about the patients was gathered and uploaded. Continuous variables (such as measurement values, scale score averages etc.) were stated as mean \pm standard deviation. Linear relationship between variables was tested by the Spearman correlation test. For the analyses between categorical variables, Chisquare Test was used. Analyses were realized by using IBB SPSS (Statistical Package Program for the Social Sciences) version 24.0 (IBM Corporation, Armonk, NY, USA). Statistical significance level was taken as $\mathrm{p}<0.05$.

\section{RESULTS}

The average age of the patients was $50.30 \pm 13.42(59.7 \%$ of them between $41-60$ years old), $64.7 \%$ percentage of the patients were women $(\mathrm{n}=194), 79.3 \%$ percentage of the patients were with type 2 diabetes $(n=238)$, and $67.7 \%$ percentage of the patients use insulin $(n=203)$. While the percentage of those who use insulin once a day was $31.6 \%$, the percentage of those who use insulin four 
times a day was $55.6 \% .85 .3 \%$ of the patients $(n=255)$ expressed that they were measuring their glucose levels themselves during the coronavirus pandemic. It was found that while the percentage of those who say the frequency of measurement was once a day was $32.1 \%$ $(\mathrm{n}=59)$, the percentage of those who say twice a day was $37.9 \%(n=69)$. The percentage of patients with 100-199 $\mathrm{mg} / \mathrm{dl}$ blood glucose level was $63.2 \%$, those with 200-300 $\mathrm{mg} / \mathrm{dl}$ was $19.9 \%$ and those with $>300 \mathrm{mg} / \mathrm{dl}$ was $4.1 \%$. $57.3 \%$ of the patients $(n=172)$ said they followed their diet during this period (Table 1).

\begin{tabular}{|c|c|}
\hline & n (\%) \\
\hline \multicolumn{2}{|l|}{ Age (year) } \\
\hline $18-40$ age & $61(20.5 \%)$ \\
\hline $41-60$ age & $178(59.7 \%)$ \\
\hline$>60$ age & $59(19.8 \%)$ \\
\hline \multicolumn{2}{|l|}{ Gender } \\
\hline Female & $194(64.7 \%)$ \\
\hline Male & $106(35.3 \%)$ \\
\hline \multicolumn{2}{|l|}{ Type of diabetes } \\
\hline Type 1 diabetes & $62(20.7 \%)$ \\
\hline Type 2 diabetes & $238(79.3 \%)$ \\
\hline \multicolumn{2}{|l|}{ Usage of Insulin } \\
\hline Yes & $203(67.7 \%)$ \\
\hline No & $97(32.3 \%)$ \\
\hline \multicolumn{2}{|c|}{ Frequency of Insulin usage (daily) } \\
\hline 1 & $62(31.6 \%)$ \\
\hline 2 & $18(9.2 \%)$ \\
\hline 3 & $7(3.6 \%)$ \\
\hline 4 & $109(55.6 \%)$ \\
\hline \multicolumn{2}{|l|}{ Measuring realised? } \\
\hline Yes & $255(85.3 \%)$ \\
\hline No & $44(14.7 \%)$ \\
\hline \multicolumn{2}{|c|}{ Measurement frequency (daily) } \\
\hline 1 & $59(32.1 \%)$ \\
\hline 2 & $69(37.9 \%)$ \\
\hline 3 & $11(6.4 \%)$ \\
\hline 4 & $28(15.1 \%)$ \\
\hline 5 and more & $14(7.5 \%)$ \\
\hline \multicolumn{2}{|c|}{ Measurement frequency (weekly) } \\
\hline 0 & $2(2.5 \%)$ \\
\hline 1 & $49(61.3 \%)$ \\
\hline 2 & $20(25.0 \%)$ \\
\hline 3 & $8(10.0 \%)$ \\
\hline 4 & $1(1.3 \%)$ \\
\hline \multicolumn{2}{|c|}{ Measurement values (mg/dl) } \\
\hline does not know & $38(12.8 \%)$ \\
\hline $100-199$ & $187(63.2 \%)$ \\
\hline $200-300$ & $59(19.9 \%)$ \\
\hline$>300$ & $12(4.1 \%)$ \\
\hline \multicolumn{2}{|l|}{ Dietary compliance } \\
\hline Yes & $172(57.3 \%)$ \\
\hline No & $128(42.7 \%)$ \\
\hline Total & $293(100 \%)$ \\
\hline
\end{tabular}

When we evaluate all the followed diabetic patients according to their glucose level, we found out that $71.1 \%$ of those who don't know their glucose level. Patients with high level glucose level (respectively 54.4\% of those with 200-300 mg/dl, $91.7 \%$ of those with $>300 \mathrm{mg} / \mathrm{dl}$ don't follow their diets; on the contrary, $69.0 \%$ of the patients $(n=129)$ with regular glucose level (those with between $100-199 \mathrm{mg} / \mathrm{dl})$ follow their diets $(\mathrm{p}<0.001)$.

It was statistically found out that the higher the blood glucose level was, the more significantly the rates of those with severe anxiety, tension and depression symptoms (excluding $>300 \mathrm{mg} / \mathrm{dl}$ ) increased $(\mathrm{p}=0.004)$. On the other hand no significant relation was found out between the excitement level and blood glucose level (Table 2).

\begin{tabular}{|c|c|c|c|c|c|c|}
\hline \multicolumn{6}{|c|}{$\begin{array}{l}\text { Table 2. Comparison of compliance with diet, a } \\
\text { depression and excitement levels according to b } \\
\text { Blood Glucose Level }\end{array}$} & \multirow[b]{2}{*}{$\mathbf{p}$} \\
\hline & $\begin{array}{c}\text { does not } \\
\text { know }\end{array}$ & $\begin{array}{c}100-199 \\
\mathrm{mg} / \mathrm{dl}\end{array}$ & $\begin{array}{c}200-300 \\
\mathrm{mg} / \mathrm{dl}\end{array}$ & $\begin{array}{c}>300 \\
\mathrm{mg} / \mathrm{dl}\end{array}$ & Total & \\
\hline \multicolumn{6}{|c|}{ Dietary compliance $(\mathrm{n}, \%)$} & $<0.001^{\star}$ \\
\hline no & $\begin{array}{c}27 \\
(71.1 \%)\end{array}$ & $\begin{array}{c}58 \\
(31.0 \%)\end{array}$ & $\begin{array}{c}32 \\
(54.2 \%)\end{array}$ & $\begin{array}{c}11 \\
(91.7 \%)\end{array}$ & $\begin{array}{c}128 \\
(43.2 \%)\end{array}$ & \\
\hline yes & $\begin{array}{c}11 \\
(28.9 \%)\end{array}$ & $\begin{array}{c}129 \\
(69.0 \%)\end{array}$ & $\begin{array}{c}27 \\
(45.8 \%)\end{array}$ & $1(8.3 \%)$ & $\begin{array}{c}168 \\
(56.8 \%)\end{array}$ & \\
\hline \multicolumn{6}{|c|}{ Score of anxiety symptoms (n,\%) } & $0.004^{\star}$ \\
\hline None & $\begin{array}{c}12 \\
(31.6 \%)\end{array}$ & $\begin{array}{c}43 \\
(23.0 \%)\end{array}$ & $\begin{array}{c}8 \\
(13.6 \%)\end{array}$ & $1(8.3 \%)$ & $\begin{array}{c}64 \\
(21.6 \%)\end{array}$ & \\
\hline Mild & $\begin{array}{c}11 \\
(28.9 \%)\end{array}$ & $\begin{array}{c}54 \\
(28.9 \%)\end{array}$ & $\begin{array}{c}14 \\
(23.7 \%)\end{array}$ & $\begin{array}{c}5 \\
(41.7 \%)\end{array}$ & $\begin{array}{c}84 \\
(28.4 \%)\end{array}$ & \\
\hline $\begin{array}{l}\text { Medium } \\
\text { severe }\end{array}$ & $\begin{array}{c}13 \\
(34.2 \%)\end{array}$ & $\begin{array}{c}60 \\
(32.1 \%)\end{array}$ & $\begin{array}{c}16 \\
(27.1 \%)\end{array}$ & $1(8.3 \%)$ & $\begin{array}{c}90 \\
(30.4 \%)\end{array}$ & \\
\hline Severe & $2(5.3 \%)$ & $\begin{array}{c}30 \\
(16.0 \%)\end{array}$ & $\begin{array}{c}21 \\
(35.6 \%)\end{array}$ & $\begin{array}{c}5 \\
(41.7 \%)\end{array}$ & $\begin{array}{c}58 \\
(19.6 \%)\end{array}$ & \\
\hline \multicolumn{6}{|c|}{ Score of tension symptoms $(\mathrm{n}, \%)$} & $0.006^{*}$ \\
\hline None & $\begin{array}{c}10 \\
(26.3 \%)\end{array}$ & $\begin{array}{c}55 \\
(29.4 \%)\end{array}$ & $\begin{array}{c}11 \\
(18.6 \%)\end{array}$ & $1(8.3 \%)$ & $77(26.0)$ & \\
\hline Mild & $\begin{array}{c}19 \\
(50.0 \%)\end{array}$ & $\begin{array}{c}60 \\
(32.1 \%)\end{array}$ & $\begin{array}{c}13 \\
(22.0 \%)\end{array}$ & $\begin{array}{c}5 \\
(41.7 \%)\end{array}$ & $97(32.8)$ & \\
\hline $\begin{array}{l}\text { Medium } \\
\text { severe }\end{array}$ & $\begin{array}{c}7 \\
(18.4 \%)\end{array}$ & $\begin{array}{c}50 \\
(26.7 \%)\end{array}$ & $\begin{array}{c}20 \\
(33.9 \%)\end{array}$ & $\begin{array}{c}2 \\
(16.7 \%)\end{array}$ & 79 (26.7) & \\
\hline Severe & $2(5.3 \%)$ & $\begin{array}{c}22 \\
(11.8 \%)\end{array}$ & $\begin{array}{c}15 \\
(25.4 \%)\end{array}$ & $\begin{array}{c}4 \\
(33.3 \%)\end{array}$ & 43 (14.5) & \\
\hline \multicolumn{6}{|c|}{ Score of depression symptoms (n,\%) } & $0.012^{*}$ \\
\hline None & $\begin{array}{c}11 \\
(28.9 \%)\end{array}$ & $\begin{array}{c}49 \\
(26.2 \%)\end{array}$ & $\begin{array}{c}7 \\
(11.9 \%)\end{array}$ & $1(8.3 \%)$ & $\begin{array}{c}68 \\
(23.0 \%)\end{array}$ & \\
\hline Mild & $\begin{array}{c}16 \\
(42.1 \%)\end{array}$ & $\begin{array}{c}66 \\
(35.3 \%)\end{array}$ & $\begin{array}{c}15 \\
(25.4 \%)\end{array}$ & $\begin{array}{c}7 \\
(58.3 \%)\end{array}$ & $\begin{array}{c}104 \\
(35.1 \%)\end{array}$ & \\
\hline $\begin{array}{l}\text { Medium } \\
\text { severe }\end{array}$ & $\begin{array}{c}8 \\
(21.1 \%)\end{array}$ & $\begin{array}{c}46 \\
(24.6 \%)\end{array}$ & $\begin{array}{c}21 \\
(35.6 \%)\end{array}$ & $\begin{array}{c}4 \\
(33.3 \%)\end{array}$ & $\begin{array}{c}79 \\
(26.7 \%)\end{array}$ & \\
\hline Severe & $3(7.9 \%)$ & $\begin{array}{c}26 \\
(13.9 \%)\end{array}$ & $\begin{array}{c}16 \\
(27.1 \%)\end{array}$ & $0(0.0 \%)$ & $\begin{array}{c}45 \\
(15.2 \%)\end{array}$ & \\
\hline \multicolumn{6}{|c|}{ Score of excitement symptoms (n,\%) } & $0.167^{\star}$ \\
\hline None & $\begin{array}{c}8 \\
(21.1 \%)\end{array}$ & $\begin{array}{c}42 \\
(22.5 \%)\end{array}$ & $4(6.8 \%)$ & $0(0.0 \%)$ & $\begin{array}{c}64 \\
(22.2 \%)\end{array}$ & \\
\hline Mild & $\begin{array}{c}11 \\
(28.9 \%)\end{array}$ & $\begin{array}{c}54 \\
(28.9 \%)\end{array}$ & $\begin{array}{c}15 \\
(25.4 \%)\end{array}$ & $\begin{array}{c}4 \\
(33.3 \%)\end{array}$ & $\begin{array}{c}81 \\
(28.1 \%)\end{array}$ & \\
\hline $\begin{array}{l}\text { Medium } \\
\text { severe }\end{array}$ & $\begin{array}{c}10 \\
(26.3 \%)\end{array}$ & $\begin{array}{c}53 \\
(28.3 \%)\end{array}$ & $\begin{array}{c}21 \\
(35.6 \%)\end{array}$ & $\begin{array}{c}4 \\
(33.3 \%)\end{array}$ & $\begin{array}{c}85 \\
(29.5 \%)\end{array}$ & \\
\hline Severe & $\begin{array}{c}9 \\
(23.7 \%)\end{array}$ & $\begin{array}{c}38 \\
(20.3 \%)\end{array}$ & $\begin{array}{c}19 \\
(32.2 \%)\end{array}$ & $\begin{array}{c}4 \\
(33.3 \%)\end{array}$ & $\begin{array}{c}58 \\
(20.1 \%)\end{array}$ & \\
\hline Total & $\begin{array}{c}38 \\
(100 \%)\end{array}$ & $\begin{array}{c}187 \\
(100 \%)\end{array}$ & $\begin{array}{c}59 \\
(100 \%)\end{array}$ & $\begin{array}{c}12 \\
(100 \%)\end{array}$ & $\begin{array}{c}296 \\
(100 \%)\end{array}$ & \\
\hline${ }^{*}$ Chi-square T & & & & & & \\
\hline
\end{tabular}




\section{DISCUSSION}

For the last few months, COVID-19 pandemic has been the most important disease in the world. Because of having a high mortality rate and high infection rate, COVID-19 causes great fear in people (9). Higher rates of comorbidities, such as hypertension (HT) and diabetes mellitus (DM), are also observed in patients hospitalized for severe disease (10).

In the management of COVID-19, home isolation has used in our country and all around the world. It is known from previous pandemics that isolation and quarantine trigger depression and anxiety (7). In this study, 298 patients with diabetes who had to stay at home we contacted by phone and asked questions about their frequency of blood glucose measurement, glucose levels, dietary compliance and mental conditions.

Some studies showed diabetes is observed as $5.6 \%$ in men and $4.2 \%$ in women. In the whole population the diabetes prevalence increases in both sexes (11). In our study, prevalence was found at similar rates $(64.7 \%$ female, $35.3 \%$ male).

Type 1 and 2 diabetes take a great role in the etiological classification of diabetes. $85 \%$ of these are type 2 diabetes (12). In our study $79.3 \%$ percentage of the patients are with type 2 diabetes as well.

It was observed that a great majority of patients use insulin and apply multiple injections. $85.3 \%$ of the patients were checking their blood glucose. When more asked, it was found that measurement frequency was quite few. The rate of the patients who were measuring 5 or more times a day was $7.5 \%$. Besides $12.8 \%$ of the patients didn't know the course of blood glucose. It was especially stated that blood glucose measurement is compulsory in diabetes management (13).

In another study, regardless of diabetes treatment, it is found that frequency of blood glucose measurement is related with the significant decrease in HgbAlc (14).

In our study we found out that the frequency of blood glucose measurement was not satisfactory. This situation may cause the deterioration of blood glucose regulation, dietary compliance and auto control. We think that patients should be encouraged more and given necessary training about the issue and we called them again.

Diet has an important role to control blood glucose regulation. Medical nutrition treatment possesses an important role in diabetes management and selfmanagement.

In the United Kingdom (UK) Prospective Study (UKPDS) a total of 30.444 people with type 2 diabetes were taken. In the whole treatment and control groups it was shown that people who were on a diet as primary protection in the first three months at the beginning of the study lost approximately 5 kilos and there was 46 $\mathrm{mg} / \mathrm{dl}$ decrease in fasting plasma glucose and $1.9 \%$ in HgbAlc (15).

In our study, we found out that $71.1 \%$ of those who don't know their blood glucose level, and patients with high level blood glucose level (respectively $54.4 \%$ of those with $200-300 \mathrm{mg} / \mathrm{dl}, 91.7 \%$ of those with $>300 \mathrm{mg} / \mathrm{dl}$ ) don't follow their diets; on the contrary, $69.0 \%$ of the patients $(n=129)$ with regular blood glucose level (those with between 100-199 mg/dl) follow their diets. We showed the importance of medical nutrition therapy in the diabetes regulation in our study. During the calls we made recommendations on the issues we realized to the patients who don't follow their diets.

In the meta-analysis, anxiety seems to be quite common in diabetes. Generalized anxiety was found in $15 \%$ of the patients and anxiety symptoms were increased in $40 \%$ of the patients. In the same meta-analysis, it is especially emphasized that there is a serious relation between anxiety and hyperglycemia in diabetic patients (16).

Stress and anxiety in diabetic patients is a potential stimulant for chronic hyperglycemia. Major effects of stress on metabolic activity have long been demonstrated. Stress causes the secretion of a number of hormones that increase blood glucose. Moreover, it is quite difficult to control hyperglycemia triggered by stress (17).

In our study we found that there was a strong relation between severity of anxiety symptoms of those who don't know their glucose levels and the patients with high glucose levels. Measuring glucose regularly ensures the person's auto- control. In this present situation, it is possible that the increase of the anxiety symptoms in patients who have to stay at home may be the reason for not measuring blood glucose.

It was found that people with anxiety, with or without hyperglycemia, had more heart rate, skin changes. As a result of this it is thought that serious anxiety triggers the increase in plasma glucose (17). As seen in previous pandemics, isolation and quarantine can trigger anxiety and depression. Similar things have been observed in people locked in who had to be away from the people they love, personal habits and lifestyles. This situation may cause disappointment, boredom, and potential depression. Avoiding from infectious diseases may increase anxiety. This anxiety situation may increase even more with improper social avoidance guidelines and less reliable media sources (7). This situation affects blood glucose regulation in a negative way, which we found a similar result in our study. 
$16 \%$ of the patients whose diabetes was regular had anxiety and $11.8 \%$ of them were found to have severe tension and it is thought that this is in the foreground related with staying at home for a long time. It is found that patients who do not know their blood glucose levels and those with high measurements also experience severe anxiety. When compared, it is seen that the depression rate in individuals with diabetes is twice as much as in those who don't have chronic diseases (18). It is stated that the risk of developing depression in diabetic patients is about $60 \%$ (19). Depression seen in people with diabetes makes metabolic control difficult, reduces the life quality, and increases the mortality and morbidity (20). In our study, it was observed that the blood glucose level was high in $27.1 \%$ of patients with severe depressive symptoms.

In our study we found a significant deterioration in diabetes regulation of the patients with severe depressive symptoms. This situation developed with staying at home seemed to have significantly affected the blood glucose regulation.

In a study, six food categories were presented. Stress didn't affect the general intake according to these six food categories but those with emotional eating preferred sweet and high-fat food more than non-stressful people. Dietary restriction didn't seem to affect the appetite in general. Especially in emotional eaters, metabolic and weight control are affected in a negative way along with increased sugar, fatty desire to eat (20).

Again in a different study, while traditional nutrition consisting of fruit, vegetables, meat and fish was found to be associated with less depressive and anxious symptoms; nutrition with unhealthy food was found to be related with more psychological symptoms and diseases.

It is understood in this study that quality of a diet is highly related with high prevalence of mental diseases especially in chronic diseases (21). It was found in our study that patients who followed their diets had significantly low tension levels, on the other hand those who did not follow their diets had specifically high tension levels. No significant relation was detected between the diet compliance and the other mental symptoms.

In our study we also found that the relation between the diet compliance and tension was significant. From a different point of view, it is possible that the tension occurred because staying home makes it difficult to follow the diet. Therefore, in this current epidemic period, the mental situation of patients with type 2 diabetes who had to stay home causes difficulty in their compliance with diet, measurement and controlling of blood sugar. It is observed that, in order to provide positive developments in the control of the disease, visits to the patients and close follow-ups are important in this period.

\begin{tabular}{|c|c|c|c|c|}
\hline & $\begin{array}{c}\text { Not } \\
\text { following } \\
\text { the diet }\end{array}$ & $\begin{array}{l}\text { Following } \\
\text { the diet }\end{array}$ & Total & $\mathbf{p}$ \\
\hline \multicolumn{4}{|c|}{ Score of anxiety symptoms (n, \%) } & $0.651^{*}$ \\
\hline None & $25(19.5 \%)$ & $40(23.3 \%)$ & $65(21.7 \%)$ & \\
\hline Mild & $35(27.3 \%)$ & $51(29.7 \%)$ & $86(28.7 \%)$ & \\
\hline Medium severe & $39(30.5 \%)$ & $51(29.7 \%)$ & $90(30.0 \%)$ & \\
\hline Severe & $29(22.7 \%)$ & $30(17.4 \%)$ & $59(19.7 \%)$ & \\
\hline \multicolumn{4}{|c|}{ Score of tension symptoms $(\mathrm{n}, \%)$} & $0.017^{*}$ \\
\hline None & $24(18.8 \%)$ & $54(31.4 \%)$ & $78(26.0 \%)$ & \\
\hline Mild & $42(32.8 \%)$ & $56(32.6 \%)$ & $98(32.7 \%)$ & \\
\hline Medium severe & $36(28.1 \%)$ & $45(26.2 \%)$ & $81(27.0 \%)$ & \\
\hline Severe & $26(20.3 \%)$ & $17(9.9 \%)$ & $43(14.3 \%)$ & \\
\hline \multicolumn{4}{|c|}{ Score of depression symptoms (n,\%) } & $0.292^{*}$ \\
\hline None & $23(18.0 \%)$ & $45(26.2 \%)$ & $68(22.7 \%)$ & \\
\hline Mild & $45(35.2 \%)$ & $61(35.5 \%)$ & $106(35.3 \%)$ & \\
\hline Medium severe & $40(31.3 \%)$ & $41(23.8 \%)$ & $81(27.0 \%)$ & \\
\hline Severe & $20(15.6 \%)$ & $25(14.5 \%)$ & $45(15.0 \%)$ & \\
\hline \multicolumn{4}{|c|}{ Score of excitement symptoms (n,\%) } & $0.167^{\star}$ \\
\hline None & $16(12.5 \%)$ & $39(22.7 \%)$ & $55(18.3 \%)$ & \\
\hline Mild & $34(26.6 \%)$ & $51(29.7 \%)$ & $85(28.3 \%)$ & \\
\hline Medium severe & $41(32.0 \%)$ & $49(28.5 \%)$ & $90(30.0 \%)$ & \\
\hline Severe & $37(28.9 \%)$ & $33(19.2 \%)$ & $70(23.3 \%)$ & \\
\hline Total & $128(100 \%)$ & $172(100 \%)$ & $300(100 \%)$ & \\
\hline
\end{tabular}

\section{CONCLUSION}

COVID-19 pandemic has been experienced worldwide including our country. Social isolation, especially staying at home, plays an important role in order to handle the pandemic. However, the high mortality and morbidity rates of the virus cause extreme fear in humanity. Also social isolation and obligation to stay at home trigger depression and anxiety. This issue may make it more difficult to ensure metabolic control of the diseases such as tip 2 diabetes which is already difficult to manage. That's why it is of great importance to support patients mentally in this process. The necessity of continuing the follow-up and education of the patients by phone or different methods arises.

\section{ETHICAL DECLARATIONS}

Ethics Committee Approval: The study was carried out with the permission of Karabük University Ethic Committee (Date 18.06.2020, Decision No: 2020/279)

Informed Consent: Because the study was designed retrospectively, no written informed consent form was obtained from patients.

Referee Evaluation Process: Externally peer-reviewed.

Conflict of Interest Statement: The author has no conflicts of interest to declare. 
Financial Disclosure: The author declared that this study has received no financial support.

Author Contributions: The author declare that they have all participated in the design, execution, and analysis of the paper, and that they have approved the final version.

Acknowledgement: We thank to Mrs. Sebnem Tanyel, Mr. Samet and Mrs. Elif Sertdemir for assistance in the translation of this article.

\section{REFERENCES}

1. Huang Y, Zhao N. Generalized anxiety disorder, depressive symptoms and sleep quality during COVID-19 outbreak in China: a web-based cross-sectional survey. Psychiatry Res 2020; 288: 112954.

2. Zhou J, Tan J. Diabetes patients with COVID-19 need better blood glucose management in Wuhan, China. Metabolism 2020; 107: 154216.

3. Öztürk Durmaz Ş, Sümer Coşkun A, Yalçın AN. Clinical and prognostic evaluation of patients admitted to the COVID-19 pandemic unit of the emergency department. J Health Sci Med 2021; 4: 835-9.

4. Wang A, Zhao W, Xu Z, Gu J. Timely blood glucose management for the outbreak of 2019 novel coronavirus disease (COVID-19) is urgently needed. Diabetes Res Clin Pract 2020; 162: 108118.

5. Guo W, Li M, Dong Y, et al. Diabetes is a risk factor for the progression and prognosis of COVID-19. Diabetes Metab Res Rev 2020; 36: e3319.

6. Franciosi M, Pellegrini F, De Berardis G, et al. QuED Study Group. The impact of blood glucose self-monitoring on metabolic control and quality of life in type 2 diabetic patients: an urgent need for better educational strategies. Diabetes Care 2001; 24: 1870-7.

7. Venkatesh A, Edirappuli S. Social distancing in COVID-19: what are the mental health implications? BMJ 2020; 369: m1379.

8. Jeong H, Yim HW, Song YJ, et al. Mental health status of people isolated due to Middle East Respiratory Syndrome. Epidemiol Health 2016; 38: e2016048.

9. Ahorsu DK, Lin CY, Imani V, Saffari M, Griffiths MD, Pakpour AH. The Fear of COVID-19 Scale: Development and Initial Validation. Int J Ment Health Addict 2020: 1-9.

10.Şahin Özdemirel T, Akkurt ES, Ertan Ö, Gökler ME, Akıncı Özyürek B. Complications with moderate-to-severe COVID-19 during hospital admissions in patients with pneumonia. J Health Sci Med 2021; 4: 766-71.

11. Forouhi NG, Wareham NJJM. Epidemiology of diabetes. 2010. 38: 602-6.

12.Schiel R, Müller UA, Rauchfub J, Sprott H, Müller R. Bloodglucose self-monitoring in insulin treated type 2 diabetes mellitus a cross-sectional study with an intervention group. Diabetes Metab 1999; 25: 334-40.

13. Karter AJ, Parker MM, Moffet HH, et al. Longitudinal study of new and prevalent use of self-monitoring of blood glucose. Diabetes Care 2006; 29: 1757-63.

14. Bergenstal RM, Gavin JR 3rd; Global Consensus Conference on Glucose Monitoring Panel. The role of self-monitoring of blood glucose in the care of people with diabetes: report of a global consensus conference. Am J Med 2005; 118: 1S-6S.

15. Pastors JG, Warshaw H, Daly A, Franz M, Kulkarni K. The evidence for the effectiveness of medical nutrition therapy in diabetes management. Diabetes Care 2002; 25: 608-13.

16. Anderson RJ, Grigsby AB, Freedland KE, et al. Anxiety and poor glycemic control: a meta-analytic review of the literature. Int J Psychiatry Med 2002; 32: 235-47.
17.Surwit RS, Schneider MS, Feinglos MN. Stress and diabetes mellitus. Diabetes Care 1992; 15: 1413-22.

18. Roy T, Lloyd CE. Epidemiology of depression and diabetes: a systematic review. J Affect Disord 2012; 142 Suppl: S8-21.

19. Bădescu SV, Tătaru C, Kobylinska L, et al. The association between Diabetes mellitus and Depression. J Med Life 2016; 9: 120-5.

20.Lustman PJ, Clouse RE. Depression in diabetic patients: the relationship between mood and glycemic control. J Diabetes Complications 2005; 19: 113-22.

21.Jacka FN, Pasco JA, Mykletun A, et al. Association of Western and traditional diets with depression and anxiety in women. Am J Psychiatry 2010; 167: 305-11. 